Article

\title{
A Glycoside Hydrolase Family 62 A-L- Arabinofuranosidase from Trichoderma Reesei and Its Applicable Potential during Mashing
}

\author{
Junyong Sun ${ }^{1,2,3,4}$, Feng $\mathrm{Xu}^{5}$ and Jian $\mathrm{Lu}^{1,2,3,4, *}$ \\ 1 The Key Laboratory of Industrial Biotechnology, Ministry of Education, Jiangnan University, Wuxi 214122, \\ Jiangsu, China; jysun@jiangnan.edu.cn \\ 2 National Engineering Laboratory for Cereal Fermentation Technology, Jiangnan University, Wuxi 214122, \\ Jiangsu, China \\ 3 School of Biotechnology, Jiangnan University, Wuxi 214122, Jiangsu, China \\ 4 Jiangsu Provincial Research Center for Bioactive Product Processing Technology, Jiangnan University, \\ Wuxi 214122, Jiangsu, China \\ 5 Wuxi Newway Biotechnology Co. Ltd., 100 Konggang Road, Wuxi 214122, Jiangsu, China; \\ xufeng618@163.com \\ * Correspondence: jlu@jiangnan.edu.cn; Tel./Fax: +86-510-85918191
}

Received: 13 February 2020; Accepted: 17 March 2020; Published: 19 March 2020 updates

\begin{abstract}
Arabinoxylan is the second most abundant component in the endosperm cell wall of barley and it has been shown to have negative effects on the viscosity and filtration rate of wort and beer. In this study, a glycoside hydrolase (GH) family $62 \alpha$-L-arabinofuranosidase (AFase), termed as TrAbf62A, was purified from the culture filtrate of Trichoderma reesei CICC 41495 by a combined chromatographic method. The preferred substrates of the purified TrAbf62A were soluble, highly substituted arabinoxylan oligosaccharides and polymers, similar to the type found in barley grain. TrAbf62A exhibited activity towards oligomeric and polymeric arabinoxylans, as well as colorimetric arabinose-based substrates, thus meeting the criteria to be classified as a type B AFase. TrAbf62A released mainly arabinose and xylose from soluble wheat arabinoxylan, thus indicating a dual lytic enzyme activity. Supplementation of TrAbf62A during mashing, with a loading of $12 \mathrm{mU} / \mathrm{g}$ malt, resulted in a $36.3 \%$ decrease in arabinoxylan polymer content, a $5.6 \%$ reduction in viscosity, and finally, a $22.1 \%$ increase in filtration rate. These results revealed that $\operatorname{Tr} A b f 62 \mathrm{~A}$ has a high potential value in improving lautering performance during mashing.
\end{abstract}

Keywords: $\alpha$-L-arabinofuranosidase; Trichoderma reesei; arabinoxylan; malted barley; mashing

\section{Introduction}

The separation of sweet wort from the mash is usually the most problematic step in the brewhouse. Poor filtration efficiency has been mainly attributed to $\beta$-glucan, which is the major non-starch polysaccharide in the cell wall of barley malt [1,2]. The main focus of improving the lautering performance of wort has been on $\beta$-glucan content and $\beta$-glucanase activity. However, when some domestic barley varieties and subsequently produced malts were used for beer brewing, even though the $\beta$-glucan content was low $(<100 \mathrm{mg} / \mathrm{L})$, the lautering performance was still poor. Latest researches have shown that arabinoxylan polymer may be involved in this phenomenon [3-7].

Arabinoxylan is the second most abundant component in the endosperm cell wall of barley [8]. Arabinoxylan consists of a $\beta$-1,4-D-xylopyranosyl backbone, substituted with arabinofuranosyl residues at $\mathrm{C}-(\mathrm{O})-2$ or $\mathrm{C}-(\mathrm{O})-3$, or at both positions [8]. The reported arabinoxylan content of commercial beers ranged from 790 to $1786 \mathrm{mg} / \mathrm{L}$ [5] and a considerable amount of it remained as arabinoxylan polymer. 
Arabinoxylan has been proven to form a highly viscous solution [3-6]. The effect of arabinoxylan on the viscosity and filtration rate of wort and beer is at least as important as that of $\beta$-glucan $[3-5,7,9,10]$.

Supplementation of microbial xylanolytic enzymes to the mash could be a good choice for the degradation of arabinoxylan and has been demonstrated to improve the filterability of wort [11-13]. The microbial xylanolytic enzyme system includes mainly xylanase (endo- $\beta-1,4-x y l a n a s e$, EC 3.2.1.8), $\alpha$-L-arabinofuranosidase (AFase) (EC 3.2.1.55), and $\beta$-D-xylosidase (EC 3.2.1.37) [14]. Xylanase is the major component of the xylanolytic enzyme system, which hydrolyses the linear $\beta-1,4$-D-xylopyranosyl backbone in the arabinoxylan. The action of xylanase drastically changes the structure and physicochemical properties of arabinoxylan. AFase is another major component of the xylanolytic enzyme system. AFase is a debranching enzyme. AFase catalyzes the hydrolysis of the arabinofuranosyl substituent from the arabinoxylan backbone, while $\beta$-D-xylosidase removes $\beta-1,4-\mathrm{D}$-xylopyranosy moieties from the terminal end of arabinoxylo-oligosaccharides and plays a key role in the complete hydrolysis of arabinoxylan [15]. To our knowledge, there has been no investigation on the arabinoxylan degradation of barley malt by microbial AFases.

The filamentous fungus Trichoderma reesei (T. reesei) is an excellent producer of xylanolytic enzymes [16,17]. Reports concerning AFases from T. reesei are quite limited. In previous work, we have found a complete xylanolytic enzyme system in the culture filtrate of T. reesei CICC 41,495 by secretome analysis [18]. This research focusses on the AFase isolated from that crude mixture of xylanolytic enzymes. Finally, a glycoside hydrolase (GH) family 62 AFase was purified to apparent homogeneity. The applicable potential of the purified AFase during Congress mashing with domestic barley malt was also evaluated. The results provide specific guidance on developing enzymatic strategies for arabinoxylan degradation during the mashing process.

\section{Materials and Methods}

\subsection{Materials and Chemicals}

T. reesei CICC 41,495 used in this study was purchased from the China Centre of Industrial Culture Collection (Beijing, China). Commercial malted barley (Hordeum vulgare L. cv. Dan'er, Chinese harvest 2017), with low $\beta$-glucan content $(96 \mathrm{mg} / \mathrm{L}$ ) and poor filtration efficiency, was obtained from a commercial malting company in the Jiangsu province of China.

Oat-spelt xylan, birchwood xylan, beechwood xylan, and 4-Nitrophenyl- $\alpha$-L-arabinofuranoside ( $p$-NPAF) were from Sigma-Aldrich (St Louis, MO, USA). Arabinoxylo-oligosaccharide was from Hualan Chemical (Shanghai, China). Soluble wheat arabinoxylan (medium viscosity) and insoluble wheat arabinoxylan were from Megazyme (Wicklow, Ireland). Sephadex G-25, DEAE-Sepharose Fast Flow and Sephacryl S-100 were from GE Healthcare (Uppsala, Sweden). The protein molar-mass marker was from Bio-Rad Laboratories (Shanghai, China). All other chemicals used were from Sinopharm Chemical Reagent Co. Ltd. (Shanghai, China), and were analytical grade.

\subsection{Enzyme Production}

T. reesei CICC 41,495 was maintained on solid potato dextrose agar slant. For enzyme production, the inoculum was prepared in Erlenmeyer flask using Mandels' medium [19]. A 10\% (v/v) inoculum culture was added to 250-mL Erlenmeyer flasks containing $50 \mathrm{~mL}$ of Mandels' medium supplemented with wheat bran at $1.0 \%(w / v)$. The flasks were incubated at $28^{\circ} \mathrm{C}$ and $200 \mathrm{rpm}$ for $168 \mathrm{~h}$. The culture filtrate was harvested by centrifugation at $8000 \times \mathrm{g}$ and $4{ }^{\circ} \mathrm{C}$ for $20 \mathrm{~min}$ and used for the purification of AFase.

\subsection{Protein Concentration Estimation}

Total protein concentration was determined using the Bradford method with bovine serum albumin (BSA) as a standard [20]. 


\subsection{Enzyme Activity Assay}

AFase activity throughout the purification procedure was determined using $p$-NPAF as the substrate $(4 \mathrm{mM})$ according to the method of Oh et al. [21]. The substrate solution $(250 \mu \mathrm{L})$ was mixed with $100 \mathrm{mM}$ sodium acetate buffer $(\mathrm{pH} 5.5,500 \mu \mathrm{L})$, and then a diluted enzyme solution $(250 \mu \mathrm{L})$ was added. The mixture was incubated at $50^{\circ} \mathrm{C}$ for $15 \mathrm{~min}$. The reaction was stopped by the addition of $1.0 \mathrm{~mL}$ of $1.0 \mathrm{M} \mathrm{Na}_{2} \mathrm{CO}_{3}$ solution. The enzyme solution boiled in a water bath for $10 \mathrm{~min}$ was used as the negative control. The absorbance was measured at $420 \mathrm{~nm}$ and the amount of $p$-nitrophenol liberated was calculated from a standard curve. One unit of activity was defined as the amount of enzyme required to liberate one $\mu \mathrm{mol} p$-nitrophenol from $p$-NPAF within one min under these conditions.

\subsection{Enzyme Purification}

To purify the AFase secreted by T. reesei CICC 41495, the crude enzyme in the culture filtrate was first fractionated by adding powdered $\left(\mathrm{NH}_{4}\right)_{2} \mathrm{SO}_{4}$ to a $20-75 \%$ saturation. The precipitate was collected by centrifugation at $8000 \times g$ for $20 \mathrm{~min}\left(4^{\circ} \mathrm{C}\right)$, dissolved in $20 \mathrm{mM}$ Tris-HCl buffer ( $\mathrm{pH} \mathrm{8.0)}$, and desalted on a Sephadex G-25 column $(1.6 \mathrm{~cm} \times 60 \mathrm{~cm})$ with the same buffer. The desalted enzyme solution was loaded onto a DEAE-Sepharose Fast Flow column $(1.6 \mathrm{~cm} \times 20 \mathrm{~cm})$ pre-equilibrated with $20 \mathrm{mM}$ Tris- $\mathrm{HCl}$ buffer ( $\mathrm{pH}$ 8.0). After washing off the unbound proteins with the starting buffer, the bound proteins were eluted by a linear gradient of $\mathrm{NaCl}(0-500 \mathrm{mM})$ in the same buffer at a flow rate of $100 \mathrm{~mL} / \mathrm{h}$. The AFase activity and the absorbance of each fraction at $280 \mathrm{~nm}\left(\mathrm{~A}_{280}\right)$ were measured, respectively. Column fractions with AFase activity were pooled and further concentrated with a 3500 Da cut-off dialysis membrane embedded in PEG20000. The concentrated active fractions were further chromatographed on a Sephacryl S-100 column $(1.6 \mathrm{~cm} \times 95 \mathrm{~cm})$ with $100 \mathrm{mM}$ sodium acetate buffer (pH 5.5) containing $150 \mathrm{mM} \mathrm{NaCl}$ at a flow rate of $20 \mathrm{~mL} / \mathrm{h}$. The active fractions were pooled, lyophilized, and stored at $-20^{\circ} \mathrm{C}$ for further analysis.

\subsection{Electrophoresis}

The homogeneity and molar mass of the purified AFase were assessed by sodium dodecyl sulfate-polyacrylamide gel electrophoresis (SDS-PAGE) with a 5.0\% $(w / v)$ stacking gel and a $12.5 \%(w / v)$ separating gel using a Mini-PROTEAN ${ }^{\circledR} 3$ Cell system (Bio-Rad, USA) [22]. Proteins were stained with Coomassie Brilliant Blue G-250 and destained in a solution containing 50\% $(v / v)$ methanol and 10\% $(v / v)$ acetic acid overnight. A low molar mass protein marker (14.3-97.2 kDa, Takara, Dalian, China) was used as the standard.

\subsection{Protein Identification}

The protein band with AFase activity was excised from the SDS-PAGE gel and digested with trypsin as described by Bienvenut et al. [23]. Spectra were acquired on Ultraflex matrix-assisted laser desorption/ionization two-stage time-of-flight tandem mass spectrometry (MALDI-TOF/TOF tandem mass spectrometry) (Bruker Daltonik, Bremen, Germany), then processed by Flexanalysis software and analyzed by Biotools software. An in-house Mascot server (http://www.matrixscience.com) was used for database searches.

\subsection{Substrate Specificity}

The substrate specificity of the purified AFase towards different arabinose-containing substrates was determined by measuring the reducing sugars in a reaction mixture. The reducing groups were measured by the 3,5-dinitrosalicylic acid (DNS) method [24]. The reaction mixture contained $500 \mu \mathrm{L}$ of the purified AFase in $100 \mathrm{mM}$ sodium acetate buffer ( $\mathrm{pH}$ 5.5) and $500 \mu \mathrm{L}$ of $1.0 \%(w / v)$ substrate solution in the same buffer. Substrates included oat-spelt xylan, birchwood xylan, beechwood xylan, soluble wheat arabinoxylan, insoluble wheat arabinoxylan, and arabinoxylo-oligosaccharide. The mixture was incubated at $50{ }^{\circ} \mathrm{C}$ for $30 \mathrm{~min}$, followed by the addition of $1.25 \mathrm{~mL}$ DNS reagent to terminate the 
reaction. After mixing well, the reaction mixture was heated for exactly $5 \mathrm{~min}$ in a boiling water bath and the volume was made up to $6.25 \mathrm{~mL}$ with ultra-pure water. The catalytic activity was determined by analyzing the reducing sugars liberated from different substrates at $540 \mathrm{~nm}$. The highest activity is defined as $100 \%$ and other activities are expressed as a percentage relative to the highest activity.

\subsection{Hydrolytic Products Analysis}

For hydrolytic products analysis, $1.0 \%(w / v)$ soluble or insoluble wheat arabinoxylan was digested at $50{ }^{\circ} \mathrm{C}$ for $16 \mathrm{~h}$. The reaction mixture $(1.0 \mathrm{~mL})$ contained $500 \mu \mathrm{L}$ of the purified AFase $(5.0 \mu \mathrm{g})$ in $100 \mathrm{mM}$ sodium acetate buffer ( $\mathrm{pH}$ 5.5) and $500 \mu \mathrm{L}$ of substrate solution in the same buffer. The reaction was terminated by boiling for $10 \mathrm{~min}$. The released sugars in the reaction mixture were analyzed by Ion Chromatography (ISC5000, Thermo Fisher Scientific, USA) fitted with a pulsed amperometric detector and a CarboPac PA20 column $(3 \mathrm{~mm} \times 150 \mathrm{~mm})$ with some modifications. The gradient elution was performed as described in the literature [25]. The flow rate was $0.50 \mathrm{~mL} / \mathrm{min}$. Arabinose and xylose were used as standards.

\subsection{Mash Preparation with Supplemented AFase}

The malt was first milled using a laboratory disc mill (Dezhijie, Beijing, China) at a fine grind setting of $0.2 \mathrm{~mm}$. Wort was prepared according to the Congress mash method outlined in the Analytica-EBC [26]: Two hundred $\mathrm{mL}$ of water were mixed with $50 \mathrm{~g}$ of finely milled malt at $46^{\circ} \mathrm{C}$ in stirred metal beakers. After continually stirring for $30 \mathrm{~min}$ at $45^{\circ} \mathrm{C}$, the temperature of the mash was increased to $70{ }^{\circ} \mathrm{C}$ at the rate of $1{ }^{\circ} \mathrm{C} / \mathrm{min}$ for $25 \mathrm{~min}$. More water $\left(100 \mathrm{~mL}, 70{ }^{\circ} \mathrm{C}\right)$ was added. The temperature was maintained at $70^{\circ} \mathrm{C}$ for $1 \mathrm{~h}$. The mash was then cooled to $20^{\circ} \mathrm{C}$. The weight of the mash was adjusted to $450 \mathrm{~g}$ by the addition of water at $20^{\circ} \mathrm{C}$. To determine the effects of the purified AFase on the viscosity and filtration rate of the wort, a dosage series of the enzyme (0-20 mU/g malt) was added to the mash with Dan'er malt at the start of the mashing process.

At the end of the mashing, the filtration rate was determined, which was defined as the volume read after $30 \mathrm{~min}$ of filtration through fluted filter paper (the first $100 \mathrm{~mL}$ filtrate was returned to the funnel). The viscosity of wort was determined at $20^{\circ} \mathrm{C}$ using a falling ball viscometer (Thermo Fisher Scientific, Germany).

For the determination of the arabinoxylan polymer content of wort, absolute ethanol was added at a final concentration of $65 \%(v / v)$ [27]. Then, the mixture was shaken vigorously and kept at $4{ }^{\circ} \mathrm{C}$ overnight. The pellets were recovered by centrifugation for $20 \mathrm{~min}\left(8000 \times \mathrm{g}, 4^{\circ} \mathrm{C}\right)$ and redissolved in ultra-pure water. The arabinoxylan polymer content in the solution was carried out according to the phloroglucinol colorimetric method presented by Douglas [28], with some adaptations. Briefly, $0.1 \mathrm{~mL}$ of wort was mixed with $1.9 \mathrm{~mL}$ of ultra-pure water. Then $10 \mathrm{~mL}$ of the phloroglucinol reagent was added. The mixture was heated in a boiling water bath for $25 \mathrm{~min}$. After cooling to room temperature, the volume in the test tube was adjusted to $25 \mathrm{~mL}$ with ultra-pure water. The arabinoxylan concentration was calculated by reading the absorbances at 510 and $552 \mathrm{~nm}$ and comparing them with the calibration curve, which was constructed with a stock solution of $100 \mathrm{mg} / \mathrm{L} \mathrm{D-(+)-xylose.}$

\section{Results and Discussion}

\subsection{Enzyme Purification}

As described in the materials and methods section, an AFase was purified to apparent electrophoretic homogeneity from the culture filtrate of T. reesei CICC 41495. Protein content and enzyme activity of each fraction were estimated at each step during the chromatography. The protein content was monitored at $280 \mathrm{~nm}$. For direct UV measurement at $280 \mathrm{~nm}$, the protein solution alone was used, without the addition of reagents, thus the measurements are quick. The AFase activity appeared as a major peak at the void volume through ion-exchange chromatography on the DEAE-Sepharose Fast Flow column, which is shown in Figure 1. Column fractions with AFase activity were pooled, 
concentrated, and further separated through gel-filtration chromatography on the Sephacryl S-100 column, and the elution profile is shown in Figure 2.

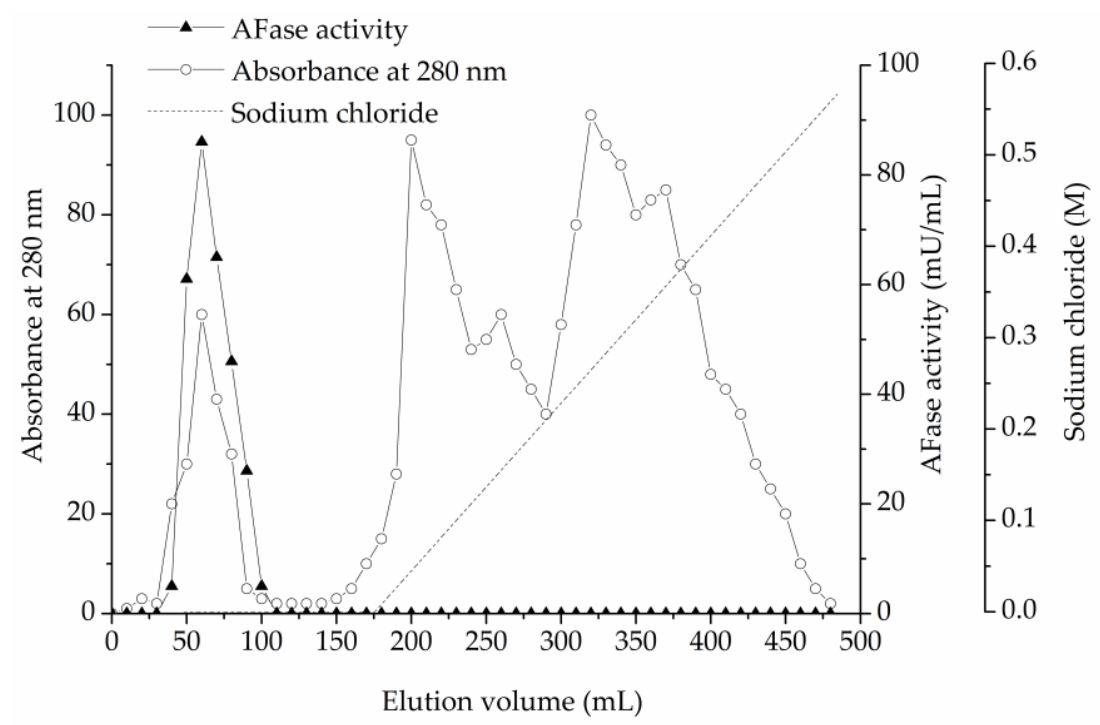

Figure 1. Ion-exchange chromatography of $\alpha$-L-arabinofuranosidase (AFase) on diethylaminoethyl (DEAE) Sepharose Fast Flow.

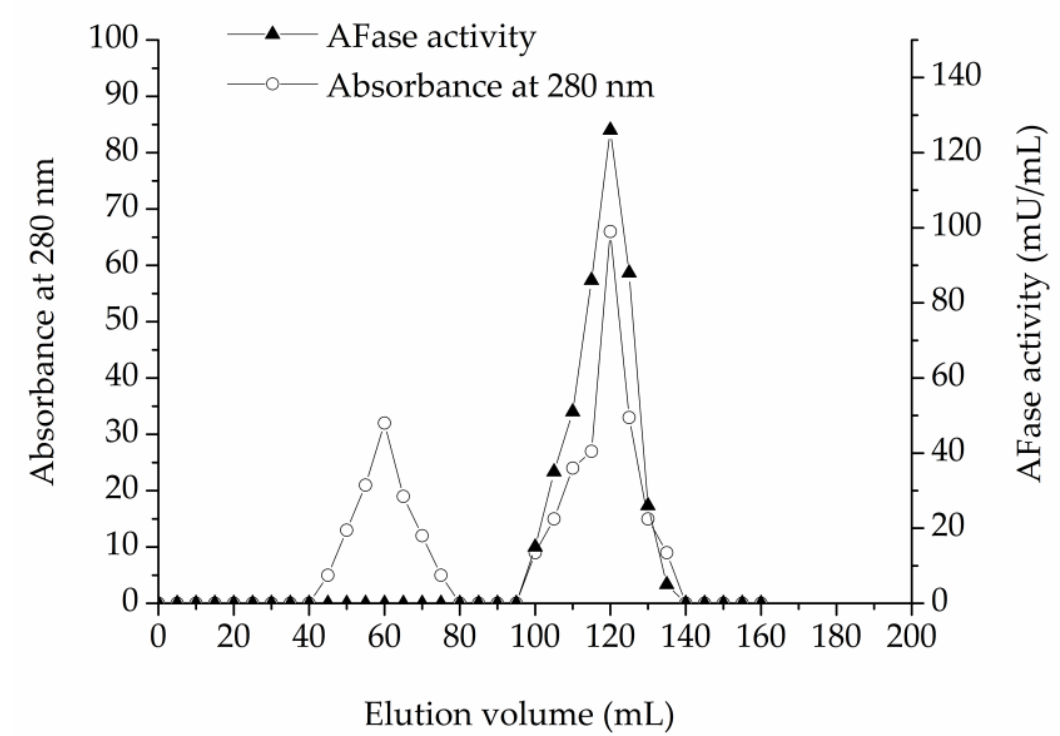

Figure 2. Gel-filtration chromatography of AFase on Sephacryl S-100.

SDS-PAGE profile of each step during the purification is shown in Figure 3. The purified AFase appeared to be a single protein band with a molar mass of $29.0 \mathrm{kDa}$ in the SDS-PAGE gel. 


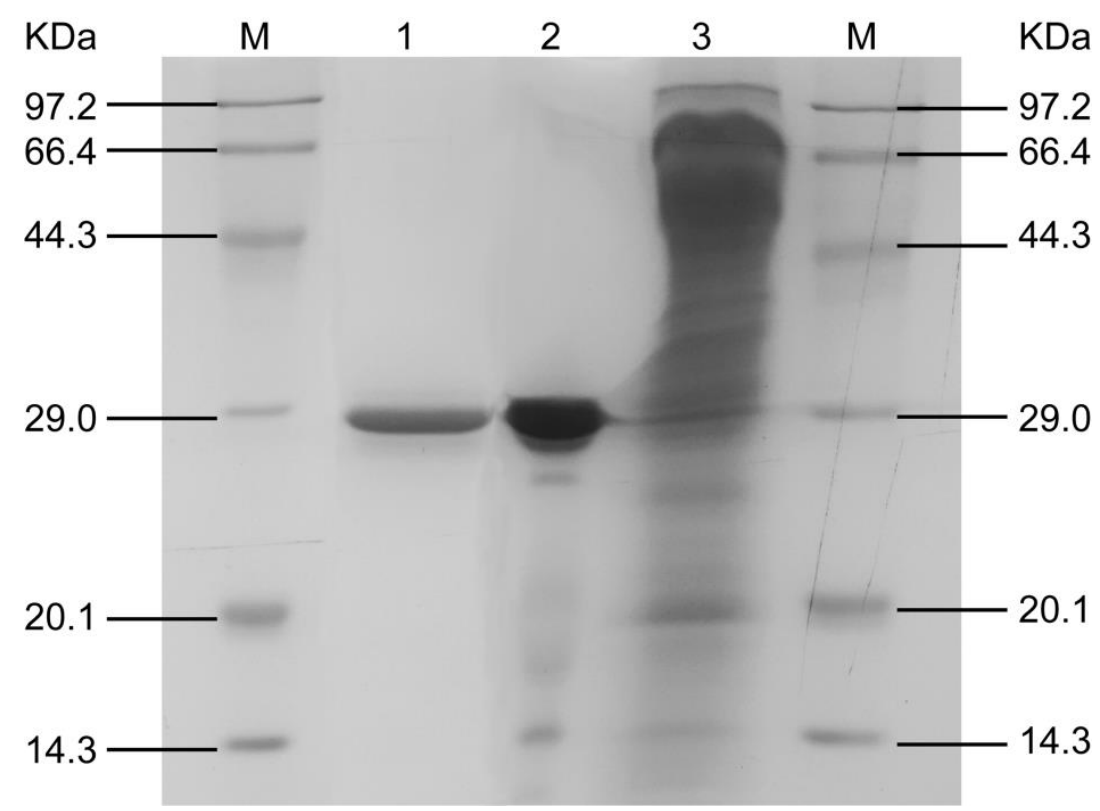

Figure 3. SDS-PAGE profiles during different stages of AFase purification. Lane 1, after Sephacryl S-100; lane 2, after DEAE-Sepharose Fast Flow; lane 3, culture filtrate; M, molar mass markers.

The protein band with AFase activity was exercised and identified as a GH62 AFase (Accession number gi|589103163) (EC 3.2.1.55, termed as TrAbf62A in this paper) by MALDI-TOF/TOF tandem mass spectrometry (Table S1). The predicted molar mass and isoelectric point of the enzyme were $34.9 \mathrm{kDa}$ and 6.4 , respectively.

The purification steps of TrAbf62A from the culture filtrate of T. reesei CICC 41,495 are summarized in Table S2. The overall purification fold of TrAbf62A was 11.2, and the yield was $26.5 \%$.

According to the similarities of the amino acid sequence, AFases are classified mainly into families GH2, GH3, GH43, GH51, GH54, and GH62 [27]. The genome of T. reesei encodes five AFases (two belonging to GH43, two belonging to GH54, and one belonging to GH62) [29-31]. Poutanen [32] first reported an AFase purified from T. reesei by cation- and anion-exchange chromatography, which was an enzyme with a molar mass of $53 \mathrm{kDa}$, isoelectric point of 7.5, and $\mathrm{pH}$ optimum of 4.0. The enzyme preferred arabinoxylo-oligosaccharides produced by the endoxylanase and could release arabinose from wheat straw and beet arabinan, but had no endoxylanase activity. An AFase with a molar mass of $35 \mathrm{kDa}$ has also been reported to be fractionated from T. reesei. Pepsin treatment showed that the $35 \mathrm{kDa}$ AFase was a result from the proteolytic cleavage of the C-terminal region of the $53 \mathrm{kDa}$ AFase [33]. However, the GH families of both AFases mentioned above are not clear. In this paper, only one AFase, which belongs to GH62, has been purified and identified, which is consistent with previous results [18]. The family GH62 exclusively contains AFases secreted by fungi or bacteria [15]. Family GH62 AFase is often not identified in the culture filtrate of $T$. reesei.

\subsection{Substrate Specificity}

The substrate specificity of an enzyme is an important property for its specific uses. The substrate specificity of TrAbf62A towards arabinoxylan polymer and arabinoxylo-oligosaccharide is summarized in Table 1. 
Table 1. Substrate specificity of TrAbf62.

\begin{tabular}{cc}
\hline Substrate $\mathbf{( 1 . 0 \% ,} \boldsymbol{w} / \boldsymbol{v})$ & Relative Activity $\mathbf{( \% )} \mathbf{~}^{\mathbf{1}}$ \\
\hline arabinoxylo-oligosaccharide & 100 \\
Oat-spelt xylan & $44.1 \pm 0.3$ \\
Soluble wheat arabinoxylan & $87.5 \pm 0.6$ \\
Insoluble wheat arabinoxylan & $7.8 \pm 0.05$ \\
Birchwood xylan & 0 \\
Beechwood xylan & 0
\end{tabular}

${ }^{1}$ Values represent the mean $\pm \mathrm{SD}(n=3)$. The highest activity is defined as $100 \%$, and the others are expressed as a relative value to the highest activity.

From the relative activities towards different arabinose-containing substrates stated in Table 1, TrAbf62A exhibited broad substrate specificity, but distinct differences were observed. TrAbf62A exhibited maximum hydrolytic activity towards arabinoxylo-oligosaccharide. TrAbf62A also showed considerable activity towards soluble wheat arabinoxylan, followed successively by oat-spelt xylan. TrAbf62A showed lower activity towards insoluble wheat arabinoxylan under the experimental conditions. The relative activity of TrAbf62A towards soluble wheat arabinoxylan was 11.2 times higher than that towards insoluble wheat arabinoxylan. No activity was detected with beechwood and birchwood xylans.

Although different arabinoxylans have the same linear backbone of the $\beta$-D-xylopyranosyl unit, their solubility, substitution degree, and substitution position are diverse. The diversity of structure and solubility between the arabinose-containing substrates used in this paper affects the relative activities of TrAbf62A. About $10.0-12.5 \%$ of the $\beta$-D-xylopyranosyl residues in oat-spelt xylan are mono-substituted by arabinofuranosyl residues at $\mathrm{C}-(\mathrm{O})-3$ and di-substituted at the $\mathrm{C}-(\mathrm{O})-2$ and $\mathrm{C}-(\mathrm{O})-3$ positions [34]. Mono-substituted $\beta$-D-xylopyranosyl units account for $12-20 \%$ and di-substituted $\beta$-D-xylopyranosyl units take up $15-30 \%$ in soluble wheat arabinoxylan, which are much higher than that in oat-spelt xylan $[35,36]$. For insoluble wheat arabinoxylan, the substitution degree is higher than that in soluble wheat arabinoxylan [37], but a lower activity of TrAbf62A towards insoluble wheat arabinoxylan was observed. This can be explained by the less-soluble nature of insoluble wheat arabinoxylan, which requires additional enzymes to make the arabinofuranosyl moieties accessible for AFases. The results showed that birchwood xylan seemed resistant to the action of TrAbf62A. Birchwood xylan is also partly insoluble and has the simplest structure and contains trace numbers of substitution [38]. The structure and solubility of beechwood xylan are similar to birchwood xylan, the activities of TrAbf62A towards them had little difference.

The substrate specificity illustrated the difference of TrAbf62A activity on arabinoxylan polymer and arabinoxylo-oligosaccharide. Based on substrate specificity, AFases are classified into three groups [39]: Group A AFases preferentially act on $p$-NPAF and arabinoxylo-oligosaccharides, and are not active towards the branched arabinoxylan polymer; group B AFases are active on $p$-NPAF, arabinoxylo-oligosaccharides, and branched arabinoxylan polymer, while group C AFases specifically catalyze the hydrolysis of branched arabinoxylan, and are inactive on $p$-NPAF. The results above showed that TrAbf62A catalyzed the hydrolysis of $p$-NPAF, arabinoxylo-oligosaccharide, and arabinofuranosyl side-branched arabinoxylan. According to the above classification method, TrAbf62A was classified into group B.

\subsection{Hydrolytic Products Analysis}

The hydrolytic products in the enzyme-substrate mixture of TrAbf62A with soluble wheat arabinoxylan and insoluble wheat arabinoxylan were analyzed by ion chromatography (Figure 4 and Figure S1, respectively). 


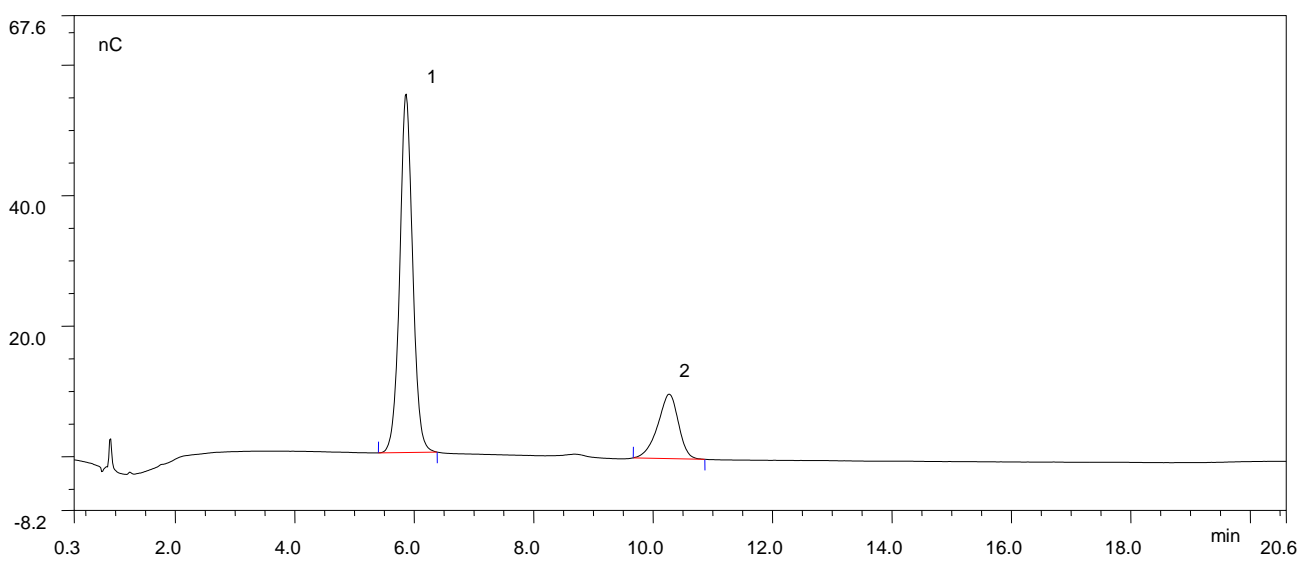

Figure 4. Chromatography profiles of the hydrolysates by TrAbf62A from soluble wheat arabinoxylan. 1 , arabinose; 2 , xylose.

According to the chromatogram (Figure 4), TrAbf62A released both arabinose (retention time $5.9 \mathrm{~min}$ ) and xylose (retention time $10.317 \mathrm{~min}$ ) from insoluble wheat arabinoxylan, accounting for $77.6 \%$ and $22.4 \%$ of the total sugars, respectively. On the contrary, there are no obvious peaks in the chromatogram (Figure S1). The chromatogram indicated that the sugar concentration in the reaction mixture with insoluble wheat arabinoxylan was low. The low sugar concentration was most likely due to the low activity of TrAbf62A on insoluble wheat arabinoxylan, which was consistent with the results in Table 1.

The sugar profile confirmed that TrAbf62A could cleave the arabinofuranosyl residues from $\beta$-D-xylopyranosyl units in branched arabinoxylan. GH62 AFases have been reported to have the capacity of liberating arabinose from arabinoxylan polymers [40-43]. Surprisingly, the chromatography profile also shows that TrAbf62A exhibited exoxylanase activity and released xylose from soluble wheat arabinoxylan. Several AFases are reported to show multifunctional activities towards arabinose-containing substrates. An AFase from radish seed (Raphanus sativus L.) has been reported to attack soluble wheat arabinoxylan in an exocleaving manner to release xylose [44]. A GH51 AFase from Alicyclobacillus sp. has also been reported to exhibit exoxylanase activity on soluble wheat arabinoxylan and sugar beet arabinan [45]. Wood and Macrae [46] reported that a GH62 AFase from Aspergillus awamori also showed the capacity to split off $\beta$-D-xylopyranosyl units from the main chain of arabinoxylan. A dual-function AFase (ARA-I) is also present in malted barley [47]. ARA-I hydrolyzes arabinoxylans at a low rate but plays an important role in the complete depolymerization of arabinoxylans through its ability to hydrolyze arabinoxylo-oligosaccharides. This implicated that there is an endogenous enzyme with similar function to TrAbf62A in the mash. The results provided more details on the mode of action of TrAbf62A. TrAbf62A showed potential for the degradation of soluble arabinoxylan in industrial biotechnology.

\subsection{Supplementation of TrAbf62A during Mashing with Barley Malt}

The efficient degradation of soluble arabinoxylan polymer in the mash during the beer brewing process is highly desirable for lautering improvement.

The Dan'er barley (Hordeum vulgare L. cv. Dan'er) is a widely cultivated variety in the Jiangsu Province of China. The characteristics of its commercial malt are listed in Table 2. 
Table 2. Characteristics of the commercial malted barley used in this manuscript.

\begin{tabular}{cc}
\hline Variable & Value \\
\hline Moisture (\%) & $4.4 \pm 0.2$ \\
Color (EBC) & $4.33 \pm 0.14$ \\
Turbidity (EBC) & $1.36 \pm 0.03$ \\
Free amino nitrogen (mg/L) & $182 \pm 2$ \\
Extract (\%) & $79.1 \pm 0.1$ \\
Total protein (\%) & $12.85 \pm 0.21$ \\
Kolbach index (\%) & $44.6 \pm 0.4$ \\
$\beta$-glucan (mg/L) & $96 \pm 3$ \\
Filtration rate (mL/30min) & $150 \pm 7$ \\
Arabinoxylan polymer content (mg/L) & $303 \pm 5$ \\
Friability (\%) & $74.2 \pm 1.2$ \\
Viscosity (mPa.s) & $1.51 \pm 0.01$ \\
\hline
\end{tabular}

For most commercial malts used for beer production in China, the filtration rate of $150 \mathrm{~mL} / 30 \mathrm{~min}$ is low, and $180-200 \mathrm{~mL} / 30 \mathrm{~min}$ is the expected value. The data in Table 2 show that the filtration efficiency of Dan'er commercial malt was poor, with low $\beta$-glucan and high arabinoxylan polymer content. This is different from the usual reason that the filtration deficiency of commercial malt is due to low Kolbach index (KI) and high $\beta$-glucan content. Maltsters and brewers have been plagued by this for years, and the commercial prospects of this domestic malt were poor; hence, TrAbf62A was supplemented during the mashing process to try to solve this problem.

The effects of TrAbf62A supplementation on the arabinoxylan polymer content, viscosity, and filtration rate during mashing are illustrated in Figure 5.

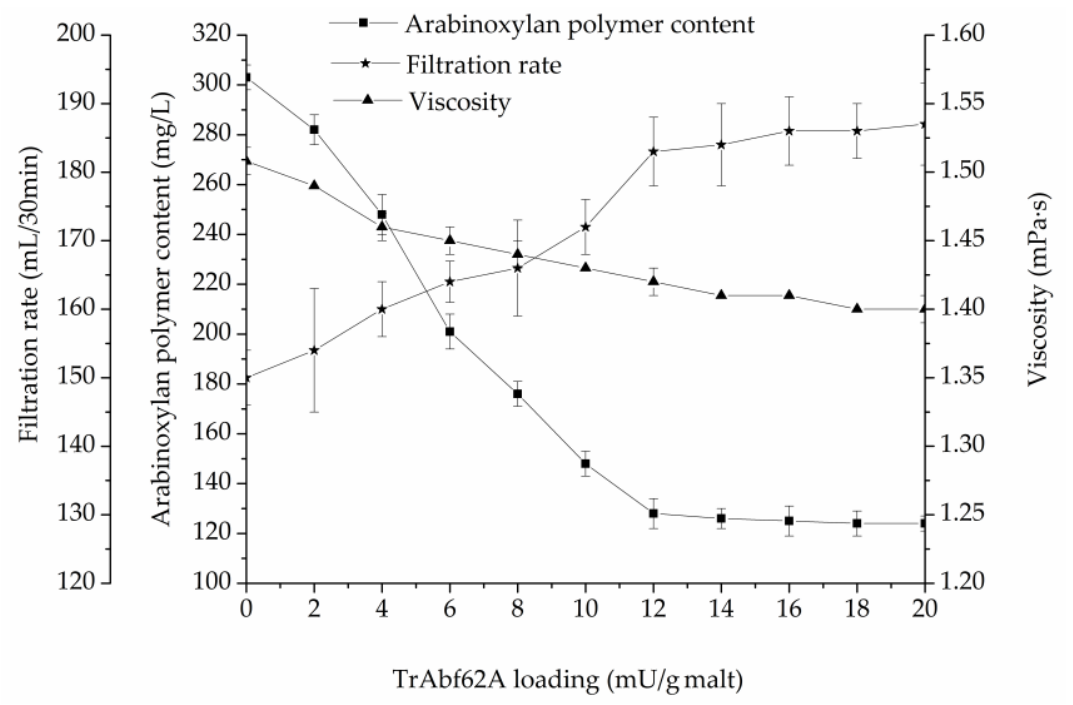

Figure 5. Effects of supplemented TrAbf62A on the arabinoxylan polymer content, viscosity, and filtration rate of wort.

The results in Figure 5 show that TrAbf62A supplementation improved the lautering performance of the mash. When TrAbf62A was supplemented at a dosage of $12 \mathrm{mU} / \mathrm{g}$ of malt, the arabinoxylan polymer content of wort decreased by $36.3 \%$, compared with the control, from $303 \mathrm{mg} / \mathrm{L}$ to $128 \mathrm{mg} / \mathrm{L}$. At the same time, the viscosity reduced by $5.6 \%$, from $1.51 \mathrm{mPa} \cdot \mathrm{s}$ to $1.42 \mathrm{mPa} \cdot \mathrm{s}$, and the filtration rate improved by $22.1 \%$, from $150 \mathrm{~mL} / 30 \mathrm{~min}$ to $183 \mathrm{~mL} / 30 \mathrm{~min}$. These indices changed little with the further increase of the TrAbf62A dosage. TrAbf62A shows an applicable potential in improving the lautering performance of barley malt during mashing. The Dan'er barley used in this paper is a widely cultivated variety in the Jiangsu Province of China. However, the high content of arabinoxylan in this variety causes filtration deficiency and makes it unusable. Supplementation of TrAbf62A increased the 
filtration rate of the Dan'er malt to near normal levels. This study provides a solution to overcome the filterability deficiency of malted barley. The malted barley can be used to replace a certain proportion of imported malted barley for beer production.

Arabinoxylan polymers precipitated with $65 \%$ ethanol from barley malt constituted of 5.1-7.1\% mono-substituted $\beta$-D-xylopyranosyl units by arabinofuranosyl residues at the C- $(O)-3$ position, 5.1-6.8\% mono-substituted at the C- $(O)-2$ position, and $24.8-28.0 \%$ di-substituted at both $\mathrm{C}-(\mathrm{O})-2$ and $\mathrm{C}-(\mathrm{O})-3$ positions to the same $\beta$-D-xylopyranosyl unit [48]. This may be the reason why the supplementation of TrAbf62A improved the lautering performance of the mash. The arabinofuranosyl residues may sterically hinder the access of some xylanases to the backbone of arabinoxylans $[49,50]$. As debranching enzymes, AFases remove the arabinofuranosyl residues linked

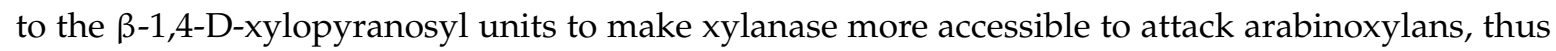
promote the degradation of arabinoxylan polymers.

\section{Conclusions}

TrAbf62A was most active against soluble, highly substituted arabinoxylan. Hydrolytic product analysis showed that TrAbf62A not only has the function of removing arabinofuranosyl residues from $\beta$-D-xylopyranosyl units, but also exhibited exoxylanase activity towards soluble wheat arabinoxylan. Supplementation of TrAbf62A during mashing decreased the arabinoxylan polymer content of wort, and as a consequence, showed performance in viscosity reduction and filtration rate improvement. $\operatorname{TrAbf62\mathrm {A}}$ has the prominent applicable potential for lautering performance improvement during mashing.

Supplementary Materials: The following are available online at http://www.mdpi.com/2304-8158/9/3/356/s1, Figure S1: Chromatography profiles of standards and the hydrolysates by TrAbf62A from soluble and insoluble wheat arabinoxylans, Table S1: Information of the protein band with AFase activity, Table S2: Purification summary of TrAbf62.

Author Contributions: Conceptualization, J.S. and J.L.; methodology, validation, and formal analysis, J.S. and F.X.; writing - original draft preparation, J.S.; reviewing and editing, J.L.; supervision, J.L. All authors have read and agreed to the published version of the manuscript.

Funding: This research was funded by the Science and Technology Project of Jiangsu Province (Modern Agriculture Project, BE2018345), the Collaborative Innovation Center of Jiangsu Modern Industrial Fermentation, the Program of Introducing Talents of Discipline to Universities (111 Project, 111-2-06), the Top-notch Academic Programs Project of Jiangsu Higher Education Institutions (TAPP), and a Project Funded by the Priority Academic Program Development of Jiangsu Higher Education Institutions.

Conflicts of Interest: The authors declare that they have no conflicts of interest.

\section{References}

1. Kanauchi, M.; Ishikura, W.; Bamforth, C.W. $\beta$-Glucans and pentosans and their degradation products in commercial beers. J. Inst. Brew. 2011, 117, 120-124. [CrossRef]

2. Kupetz, M.; Aumer, J.; Harms, D.; Zarnkow, M.; Sacher, B.; Becker, T. High-throughput $\beta$-glucan analyses and their relationship with beer filterability. Eur. Food Res. Technol. 2017, 243, 341-351. [CrossRef]

3. Stewart, D.C.; Hawthorne, D.; Evans, D.E. Cold sterile filtration: A small scale filtration tests and investigation of membrane plugging. J. Inst. Brew. 1998, 104, 321-326. [CrossRef]

4. Sadosky, P.; Schwarz, P.; Horsley, R. Effect of arabinoxylans, $\beta$-glucans, and dextrins on the viscosity and membrane filterability of a beer model solution. J. Am. Soc. Brew. Chem. 2002, 60, 153-162. [CrossRef]

5. Li, M.M.; Du, J.H.; Zheng, Y.X. Non-starch polysaccharides in wheat beers and barley malt beers: A comparative study. Foods 2020, 9, 131. [CrossRef]

6. Rosicka-Kaczmarek, J.; Komisarczyk, A.; Nebesny, E.; Makowski, B. The influence of arabinoxylans on the quality of grain industry products. Eur. Food Res. Technol. 2016, 242, 295-303. [CrossRef]

7. Kupetz, M.; Zeh, A.; Fischer, S.; Becker, T. Investigation of filtration-inhibitory substances in german wheat beer. Brew. Sci. 2017, 70,1-8. 
8. Hassan, A.S.; Houston, K.; Lahnstein, J.; Shirley, N.; Schwerdt, J.G.; Gidley, M.J.; Waugh, R.; Little, A.; Burton, R.A. A genome wide association study of arabinoxylan content in 2-row spring barley grain. PLoS ONE 2017, 12, e0182537. [CrossRef]

9. Stewart, D.; Freeman, G.; Evans, E. Development and assessment of a small-scale wort filtration test for the prediction of beer filtration efficiency. J. Inst. Brew. 2000, 106, 361-366. [CrossRef]

10. Li, Y.; Lu, J.; Gu, G.X.; Shi, Z.P.; Mao, Z.G. Studies on water-extractable arabinoxylans during malting and brewing. Food Chem. 2005, 93, 33-38. [CrossRef]

11. Du, Y.L.; Shi, P.J.; Huang, H.Q.; Zhang, X.; Luo, H.Y.; Wang, Y.R.; Yao, B. Characterization of three novel thermophilic xylanases from Humicola insolens $\mathrm{Y} 1$ with application potentials in the brewing industry. Bioresour. Technol. 2013, 130, 161-167. [CrossRef] [PubMed]

12. Zhao, L.; Meng, K.; Bai, Y.G.; Shi, P.J.; Huang, H.Q.; Luo, H.Y.; Wang, Y.R.; Yang, P.L.; Song, W.; Yao, B. Two family 11 xylanases from Achaetomium sp. Xz-8 with high catalytic efficiency and application potentials in the brewing industry. J. Agric. Food Chem. 2013, 61, 6880-6889. [CrossRef] [PubMed]

13. Wang, X.Y.; Luo, H.Y.; Yu, W.N.; Ma, R.; You, S.; Liu, W.N.; Hou, L.Y.; Zheng, F.; Xie, X.M.; Yao, B. A thermostable Gloeophyllum trabeum xylanase with potential for the brewing industry. Food Chem. 2016, 199, 516-523. [CrossRef]

14. Walia, A.; Guleria, S.; Mehta, P.; Chauhan, A.; Parkash, J. Microbial xylanases and their industrial application in pulp and paper biobleaching: A review. 3 Biotech 2017, 7, 11. [CrossRef]

15. Wilkens, C.; Andersen, S.; Dumon, C.; Berrin, J.G.; Svensson, B. GH62 arabinofuranosidases: Structure, function and applications. Biotechnol. Adv. 2017, 35, 792-804. [CrossRef]

16. Bischof, R.H.; Ramoni, J.; Seiboth, B. Cellulases and beyond: The first 70 years of the enzyme producer Trichoderma reesei. Microb. Cell Fact. 2016, 15, 106. [CrossRef]

17. Ramoni, J.; Marchetti-Deschmann, M.; Seidl-Seiboth, V.; Seiboth, B. Trichoderma reesei xylanase 5 is defective in the reference strain QM6a but functional alleles are present in other wild-type strains. Appl. Microbiol. Biotechnol. 2017, 101, 4139-4149. [CrossRef]

18. Sun, J.Y.; Lu, J.; Xie, G.F. Secretome analysis of Trichoderma reesei CICC41495 for degradation of arabinoxylan in malted barley. J. Inst. Brew. 2018, 124, 352-358. [CrossRef]

19. Mandels, M.; Weber, J. The production of cellulases. Adv. Chem. 1969, 95, 391-414.

20. Bradford, M.M. A rapid and sensitive method for the quantitation of microgram quantities of protein utilizing the principle of protein-dye binding. Anal. Biochem. 1976, 72, 248-254. [CrossRef]

21. Oh, G.W.; Kang, Y.; Choi, C.Y.; Kang, S.Y.; Kang, J.H.; Lee, M.L.; Han, N.S.; Kim, T.J. Detailed mode of action of arabinan-debranching $\alpha$-L-arabinofuranosidase GH51 from Bacillus velezensis. J. Microbiol. Biotechnol. 2019, 29, 37-43. [CrossRef]

22. Laemmli, U.K. Cleavage of structural protein during the assembly of the head of bacteriophage T4. Nature 1970, 227, 680-685. [CrossRef] [PubMed]

23. Bienvenut, W.V.; Déon, C.; Pasquarello, C.; Campbell, J.M.; Sanchez, J.C.; Vestal, M.L.; Hochstrasser, D.F. Matrix-assisted laser desorption/ionization-tandem mass spectrometry with high resolution and sensitivity for identification and characterization of proteins. Proteomics 2002, 2, 868-876. [CrossRef]

24. Miller, G.L. Use of dinitrosalicylic acid reagent for determination of reducing sugar. Anal. Biochem. 1959, 31, 426-428. [CrossRef]

25. Wu, S.J. Mulberry leaf polysaccharides suppress renal fibrosis. Int. J. Biol. Macromol. 2019, 124, 1090-1093. [CrossRef] [PubMed]

26. European Brewery Convention. Analytica-EBC, 5th ed.; Fachverlag Hans Carl: Nürnberg, Germany, 1998; Volume 4, pp. 1-3.

27. Cleemput, G.; Roels, S.P.; Van Oort, M.; Grobet, J.; Delcour, J.A. Heterogeneity in the structure of water-soluble arabinoxylans in European wheat flours of variable bread-making quality. Cereal Chem. 1993, 70, 324-329.

28. Douglas, S.G. A rapid method for the determination of pentosans in wheat flour. Food Chem. 1981, 7, 139-145. [CrossRef]

29. Martinez, D.; Berka, R.M.; Henrissat, B.; Saloheimo, M.; Arvas, M.; Baker, S.E.; Chapman, J.; Chertkov, O.; Coutinho, P.M.; Cullen, D.; et al. Genome sequencing and analysis of the biomass-degrading fungus Trichoderma reesei (syn. Hypocrea jecorina). Nat. Biotechnol. 2008, 26, 553-560. [CrossRef] [PubMed] 
30. Gupta, V.K.; Schmoll, M.; Herrera-Estrella, A.; Upadhyay, R.S.; Druzhinina, I.; Tuohy, M.G. Biotechnology and Biology of Trichoderm, 3rd ed.; Elsevier: Amsterdam, The Netherlands, 2014; pp. 339-344.

31. Gong, W.L.; Zhang, H.Q.; Liu, S.J.; Zhang, L.L.; Gao, P.J.; Chen, G.J.; Wang, L.S. Comparative secretome analysis of Aspergillus niger, Trichoderma reesei, and Penicillium oxalicum during solid-state fermentation. Appl. Biochem. Biotechnol. 2015, 177, 1252-1271. [CrossRef] [PubMed]

32. Poutanen, K. An $\alpha$-L-arabinofuranosidase of Trichoderma reesei. J. Biotechnol. 1988, 7, 271-281. [CrossRef]

33. Nogawa, M.; Yatsui, K.; Tomioka, A.; Okada, H.; Morikawa, Y. An $\alpha$-L-arabinofuranosidase from Trichoderma reesei containing a noncatalytic xylan-binding domain. Appl. Environ. Microbiol. 1999, 65, 3964-3968. [CrossRef] [PubMed]

34. Kormelink, F.J.M.; Voragen, A.G.J. Degradation of different [(glucurono)arabino]xylans by a combination of purified xylan-degrading enzymes. Appl. Microbiol. Biot. 1993, 38, 688-695. [CrossRef]

35. Barron, C.; Robert, P.; Guillon, F.; Saulnier, L.; Rouau, X. Structural heterogeneity of wheat arabinoxylans revealed by Raman spectroscopy. Carbohydr. Res. 2006, 341, 1186-1191. [CrossRef] [PubMed]

36. Geng, A.L.; Wu, J.; Xie, R.G.; Wang, H.C.; Wu, Y.F.; Li, X.; Chang, F.X.; Sun, J.Z. Highly thermostable GH51 $\alpha$-arabinofuranosidase from Hungateiclostridium clariflavum DSM 19732. Appl. Microbiol. Biot. 2019, 103, 3783-3793. [CrossRef] [PubMed]

37. Sørensen, H.R.; Pedersen, S.; Meyer, A.S. Synergistic enzyme mechanisms and effects of sequential enzyme additions on degradation of water insoluble wheat arabinoxylan. Enzyme Microb. Technol. 2007, 40, 908-918. [CrossRef]

38. Adams, E.L.; Kroon, P.A.; Williamson, G.; Gilbert, H.J.; Morris, V.J. Inactivated enzymes as probes of the structure of arabinoxylans as observed by atomic force microscopy. Carbohydr. Res. 2004, 339, 579-590. [CrossRef]

39. Phuengmaunga, P.; Kunishigeb, Y.; Sukhumsiricharta, W.; Sakamotob, T. Identification and characterization of GH62 bacterial $\alpha$-L-arabinofuranosidase from thermotolerant Streptomyces sp. SWU10 that preferentially degrades branched L-arabinofuranoses in wheat arabinoxylan. Enzyme Microb. Technol. 2018, 112, $22-28$. [CrossRef]

40. Vincent, P.; Shareck, F.; Dupont, C.; Kluepfel, D. New $\alpha$-L-arabinofuranosidase produced by Streptomyces lividans: Cloning and DNA sequence of the abfB gene and characterization of the enzyme. Biochem. J. 1997, 15, 845-852. [CrossRef]

41. Sakamoto, T.; Ogura, A.; Inui, M.; Tokuda, S.; Hosokawa, S.; Kasai, N. Identification of a GH62 $\alpha$-L-arabinofuranosidase specific for arabinoxylan produced by Penicillium chrysogenum. Appl. Microbiol. Biotechnol. 2011, 90, 137-146. [CrossRef]

42. Hu, Y.B.; Yan, X.C.; Zhang, H.; Liu, J.Q.; Luo, F.; Cui, Y.Y.; Wang, W.Y.; Zhou, Y.F. Cloning and expression of a novel $\alpha-1,3$-arabinofuranosidase from Penicillium oxalicum sp. 68. AMB Express 2018, 8, 51. [CrossRef]

43. Sarch, C.; Suzuki, H.; Master, E.R.; Wang, W.J. Kinetics and regioselectivity of three GH62 $\alpha$-L-arabinofuranosidases from plant pathogenic fungi. Biochim. Biophys. Acta Gen. Subj. 2019, 1863, 1070-1078. [CrossRef] [PubMed]

44. Hata, K.; Tanaka, M.; Tsumuraya, Y.; Hashimoto, Y. $\alpha$-L-Arabinofuranosidase from radish (Raphanus sativus L.) seeds. Plant Physiol. 1992, 100, 388-396. [CrossRef] [PubMed]

45. Yang, W.X.; Bai, Y.G.; Yang, P.L.; Luo, H.Y.; Huang, H.Q.; Meng, K.; Shi, P.J.; Wang, Y.R.; Yao, B. A novel bifunctional GH51 exo- $\alpha$-L-arabinofuranosidase/endo-xylanase from Alicyclobacillus sp. A4 with significant biomass-degrading capacity. Biotechnol. Biofuels 2015, 8, 197. [CrossRef] [PubMed]

46. Wood, T.M.; Macrae, S.I. Arabinoxylan-degrading enzymes systems of the fungus Aspergillus awamori: Purification and properties of an $\alpha$-L-arabinofuranosidase. App. Microbiol. Biotechnol. 1996, 45, 538-545. [CrossRef]

47. Lee, R.C.; Hrmova, M.; Burton, R.A.; Lahnstein, J.; Fincher, G.B. Bifunctional family 3 glycoside hydrolases from barley with $\alpha$-L-arabinofuranosidase and $\beta$-D-xylosidase activity. Characterization, primary structures, and COOH-terminal processing. J. Biol. Chem. 2003, 278, 5377-5387. [CrossRef]

48. Debyser, W.; Schooneveld-Bergmans, M.E.F.; Derdelinckx, G.; Grobet, P.J.; Delcour, J.A. Nuclear magnetic resonance and methylation analysis-derived structural features of water-extractable arabinoxylans from barley (Hordeum vulgare L.) malts. J. Agric. Food Chem. 1997, 45, 2914-2918. [CrossRef] 
49. Mechelke, M.; Koeck, D.E.; Broeker, J.; Roessler, B.; Krabichler, F.; Schwarz, W.H.; Zverlov, V.V.; Liebl, W. Characterization of the arabinoxylan-degrading machinery of the thermophilic bacterium Herbinix hemicellulosilytica-Six new xylanases, three arabinofuranosidases and one xylosidase. J. Biotechnol. 2017, 257, 122-130. [CrossRef]

50. Thakur, A.; Sharma, K.; Goyal, A. $\alpha$-L-Arabinofuranosidase: A potential enzyme for the food industry. In Green Bio-Processes Enzymes in Industrial Food Processing; Agarwal, A.K., Pandey, A., Eds.; Springer: Singapore, 2019; pp. 229-244.

(C) 2020 by the authors. Licensee MDPI, Basel, Switzerland. This article is an open access article distributed under the terms and conditions of the Creative Commons Attribution (CC BY) license (http://creativecommons.org/licenses/by/4.0/). 